\title{
Short-Term Cost-Effectiveness of Switching to Insulin Degludec in Japanese Patients with Type 2 Diabetes Receiving Basal-Bolus Therapy
}

\author{
Jakob Langer · Michael L. Wolden - Seiya Shimoda • Miki Sato • \\ Eiichi Araki
}

Received: January 31, 2019 / Published online: June 5, 2019

(C) The Author(s) 2019

\section{ABSTRACT}

Introduction: With one of the fastest aging populations in the world, demographic changes in Japan are a major public health concern due to the substantial burden that aging-associated diseases, such as type 2 diabetes (T2D), place on public healthcare systems. The aim of this analysis was to evaluate the short-term cost-effectiveness of switching Japanese patients with T2D receiving basal-bolus insulin therapy from their previous basal insulin to insulin degludec (degludec) under conditions of routine clinical practice.

Methods: A previously published, open-source model developed in Microsoft Excel was used to

Enhanced Digital Features To view enhanced digital features for this article go to https://doi.org/10.6084/ m9.figshare.8118215.

Electronic Supplementary Material The online version of this article (https://doi.org/10.1007/s13300019-0635-1) contains supplementary material, which is available to authorized users.

J. Langer $(\bowtie)$

Novo Nordisk Pharma Ltd., Tokyo, Japan

e-mail: JKLG@novonordisk.com

M. L. Wolden

Novo Nordisk A/S, Søborg, Denmark

S. Shimoda

Prefectural University of Kumamoto, Kumamoto, Japan

M. Sato · E. Araki

Kumamoto University, Kumamoto, Japan evaluate the cost-effectiveness of switching basal-bolus insulin therapy from patients' previous basal insulin to degludec versus continuing the previous basal insulin therapeutic regimen in terms of costs (2018 Japanese Yen [JPY]) and quality-adjusted life years (QALYs), from a Japanese public healthcare payer perspective. The model captured hypoglycemia rates and insulin dosing over a 1-year time horizon, and was informed by Japanese realworld evidence from the T2D cohort $(N=135)$ of the Kumamoto Insulin Degludec Observational study.

Results: Treatment with degludec was associated with improved effectiveness ( +0.0354 QALYs), driven by lower daytime non-severe hypoglycemia rates with degludec, at slightly higher annual treatment costs (JPY 9510) versus continuing the previous basal insulin. Switching basal insulin to degludec was found to be a cost-effective intervention with an incremental cost-effectiveness ratio (JPY 268,811 per QALY gained) substantially below the willingness-to-pay threshold of 5 million JPY per QALY used in the Japanese Health Technology Assessment framework. Sensitivity analyses confirmed the robustness of this finding and indicated that the daytime non-severe hypoglycemia benefit with degludec was a key driver of outcomes in the base case.

Conclusion: Based on Japanese real-world evidence, our analysis suggests that switching Japanese patients with $\mathrm{T} 2 \mathrm{D}$ receiving a basal-bolus regimen from their previous basal 
insulin to degludec would be highly cost-effective. These data may help decision-makers in Japan allocate healthcare resources efficiently.

Trial Registration: The KIDUNA study is registered with the University Hospital Medical Information Network Clinical Trials Registry (UMIN-CTR): UMIN000021569.

Funding: Novo Nordisk Pharma Ltd. Japan.

Keywords: Cost-effectiveness analysis; Health economics; Hypoglycemia; Insulin degludec; Japan; QALY; Real-world evidence; Type 2 diabetes

\section{INTRODUCTION}

Over the past few decades Japan has ranked highly in a number of population health metrics, including the world's longest life expectancy, despite its relatively low per capita healthcare expenditure [1]. However, the Japanese healthcare system is currently facing significant challenges due to demographic changes and the increasing cost of new technologies in conjunction with modest economic growth, which together have resulted in increasing healthcare expenditure (2005: $7.8 \%$ gross domestic product [GDP]; 2015: 10.9\% GDP) [2]. In response to a rising demand for healthcare from an aging population and growing public financial constraints, Japan introduced a pilot Health Technology Assessment (HTA) program in 2016 [3]. While economic evaluation supports healthcare decision-making in many countries [4], it was relatively unused in Japanese decision-making in the healthcare sector prior to this initiative [3]. The HTA systematically examines the safety, clinical effectiveness, costs and any legal, ethical or social implications of a drug, medical device or clinical procedure. Cost-effectiveness analyses (CEAs), which frequently form an important part of the HTA, compare the costs of new interventions with their outcomes measured in utility units, most commonly the quality-adjusted life-year (QALY), and capture both quantity- and quality-of-life. CEAs are an important tool to assist healthcare systems in deciding how to allocate resources efficiently between interventions to achieve maximal healthcare gains within a fixed budget [5].

Diabetes is a major public health concern due to its high prevalence and the associated morbidity, mortality and economic burden of diabetes-related complications [6]. While the prevalence of diabetes in Japan has remained relatively stable over the past 20 years, except for an increasing trend in elderly age groups [2], it is expected to increase in Japan from $7.9 \%$ in 2010 to $9.8 \%$ by 2030 [7]. Hypoglycemia is a common and serious side effect of many of the agents used to treat type 2 diabetes (T2D), including insulins, sulphonylureas and glinides [8]. The unpleasant symptoms associated with hypoglycemia can lead to significant anxiety with regard to future events and considerable negative effects on patient quality-of-life, along with significant economic burden through increased healthcare resource utilization $[9,10]$. Hypoglycemia and the fear of hypoglycemia are considered to be limiting factors to optimal glycemic control, affecting both diabetes management and clinical outcomes [8]. In particular, severe hypoglycemic events are associated with a heightened risk of a range of poor clinical outcomes and complications [11-13].

Insulin degludec (degludec) is a basal insulin with an ultra-long duration of action and stable glucose-lowering profile [14]. Randomized controlled trials (RCTs) have confirmed that similar improvements in glycemic control can be achieved with fewer hypoglycemic episodes across a broad spectrum of patients with diabetes receiving degludec versus insulin glargine $100 \mathrm{U} /$ $\mathrm{mL}$ (glargine U100) [15-18]. From public healthcare payer perspectives over short-term time horizons (1-2 years), degludec has been shown to be cost-effective compared with glargine U100 in patients with type 1 diabetes (T1D) or T2D across a range of global settings [19-26].

The aim of the present analysis was to evaluate the short-term cost-effectiveness of switching Japanese patients with $\mathrm{T} 2 \mathrm{D}$ receiving basal-bolus insulin therapy from their previous basal insulin to degludec. This analysis was conducted from a Japanese public healthcare payer perspective and was informed by Japanese real-world data from the Kumamoto Insulin Degludec Observational (KIDUNA) study. 


\section{METHODS}

\section{The KIDUNA Study}

The design and primary results of the KIDUNA study have been published previously [27]. In brief, KIDUNA was a 1-year, prospective, openlabel, multicenter, non-randomized, treat-totarget observational study in adult Japanese outpatients with T1D or T2D receiving a basal-bolus insulin regimen. The study included patients with T1D or T2D treated with glargine U100 or insulin detemir (IDet) and a rapid-acting insulin analog who were switched from basal insulin to degludec once-daily (at bedtime) under conditions of routine clinical practice. Any concomitant oral antidiabetic drugs were continued at their pre-switch dose throughout the study.

Body mass index (BMI), glycated hemoglobin $\left(\mathrm{HbA}_{1 \mathrm{c}}\right)$ and insulin dose were monitored at baseline (just prior to the switch from basal insulin to degludec) and at specified intervals over a 1-year period post-switch. Hypoglycemia rates were compared pre- and post-switch (in the month prior to switching from basal insulin to degludec and in the period 3-6 months after switching, respectively). In KIDUNA, non-severe hypoglycemia was defined as self-reported symptoms of hypoglycemia and/or blood glucose level of $<70 \mathrm{mg} / \mathrm{dL} \quad(3.9 \mathrm{mmol} / \mathrm{L})$, and nocturnal events were defined as those occurring between 0001 and 0559 hours (both inclusive). Severe hypoglycemia was defined as hypoglycemia accompanied by severe central nervous system symptoms that could not be resolved by the patient and required assistance.

\section{Model Overview}

A previously published, open-source model developed in Microsoft Excel [26] was used to evaluate the short-term cost-effectiveness of switching basal insulin to degludec versus continuing the previous basal insulin in terms of costs (2018 Japanese Yen [JPY]) and QALYs, from a Japanese public healthcare payer perspective (Fig. 1 displays the model schematic). The model captured hypoglycemia rates and insulin dosing over a 1-year time horizon, and was informed by the clinical outcomes and baseline characteristics of the T2D cohort $(N=135)$ of the KIDUNA study (Tables 1,2$)$. Baseline data were extrapolated for a hypothetical patient cohort who continued their previous basal insulin regimen (cost of glargine U100 assumed), in order to make the comparison with the degludec simulation arm. Body weight was not captured by the model, as there was no significant difference in BMI after 12 months of treatment with degludec versus at baseline in the KIDUNA T2D cohort (Electronic Supplementary Material [ESM] Table S1) [27].

\section{Event Rates and Insulin Doses}

Treatment differences in clinical outcomes were estimated using rate and dose ratios based on the results from the KIDUNA T2D cohort in the periods before and after the patients were switched to degludec (ESM Table S1). The model only captured treatment effects if there was a statistically significant difference between treatment arms; otherwise the previous basal insulin event rate or dose was assumed for both simulation arms. As the primary analysis of the KIDUNA T2D cohort reported no significant differences in basal or bolus insulin dose requirements following 12 months of treatment with degludec versus the baseline dose of the previous basal insulin [27], insulin doses were modeled as end-of-study doses in both simulation arms and a mean end-of-study body weight of $65 \mathrm{~kg}$ was assumed (derived from the mean baseline BMI value of $25.0 \mathrm{~kg} / \mathrm{m}^{2}$ reported in the KIDUNA study).

\section{Costs and Utilities}

Conservatively, no costs were associated with hypoglycemic events, as (1) there are no Japanese-specific costs for non-severe hypoglycemic events available in the literature, and (2) there were no severe hypoglycemic events recorded for the KIDUNA T2D cohort pre- or post-switch [27] (ESM Table S1). Health-related quality-oflife utilities were extracted from the literature (Table 3). Assumptions in the base case analysis 
Treatment cost

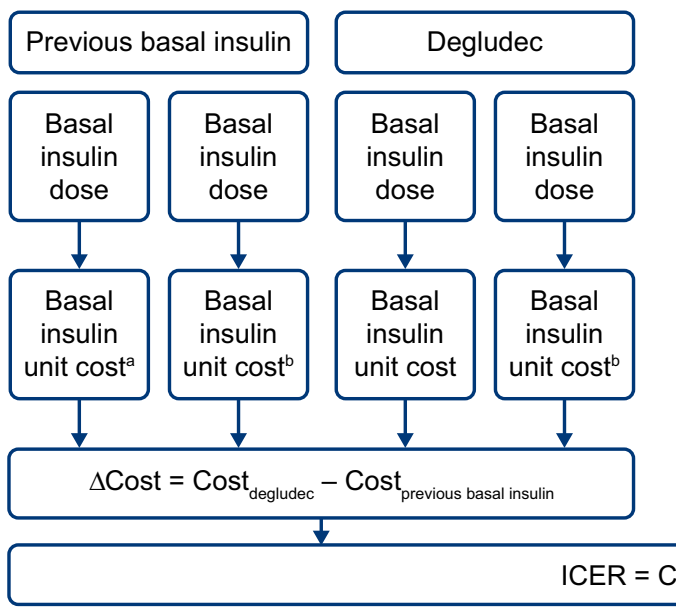

Fig. 1 Schematic illustration of the cost-effectiveness model. Basal and bolus insulin doses were modeled as the pre-switch dose for the type 2 diabetes (T2D) Kumamoto Insulin Degludec Observational (KIDUNA) study cohort in both simulation arms. Non-severe hypoglycemia was defined as self-reported symptoms of hypoglycemia and/or a blood glucose level of $<70 \mathrm{mg} / \mathrm{dL}$ $(3.9 \mathrm{mmol} / \mathrm{L})$ and defined as nocturnal if occurring

included a utility associated with the flexible degludec dosing schedule.

\section{Sensitivity Analyses}

Deterministic sensitivity analyses were conducted to identify key drivers of outcomes in the base case analysis. These included one-way, exploratory analyses excluding the utility associated with the flexible dosing of degludec, removing treatment differences in daytime or nocturnal non-severe hypoglycemia rates or varying the basal insulin cost in the comparator arm to the cost of biosimilar glargine. Two-way sensitivity analyses were conducted with each of the aforementioned one-way analyses in conjunction with the basal insulin cost of biosimilar glargine in the comparator arm.

\section{Compliance with Ethics Guidelines}

All participants provided written, informed consent to participate in the KIDUNA study, which was carried out in accordance with the
HRQoL

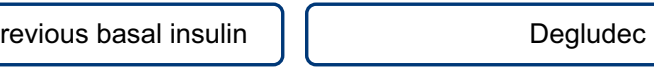

Degludec

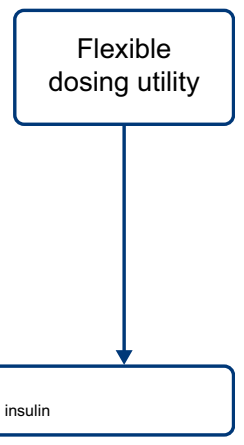

$\triangle Q A L Y s=Q A L Y s_{\text {degludec }}-Q A L Y s_{\text {previous basal insulin }}$

更 non-severe hypoglycemia rate

Nocturnal hypoglycemia rate

Disutility per event

between 0001 and 0559 hours (both inclusive), otherwise defined as daytime. ${ }^{\text {a }}$ Costs calculated for insulin glargine $100 \mathrm{U} / \mathrm{mL}$ (glargine U100); ${ }^{b}$ costs calculated for insulin aspart; ' ${ }^{c}$ estimated rate ratio $(E R R)$ calculated for degludec versus previous basal insulin for the T2D cohort of the KIDUNA study. HRQoL Health-related quality-of-life, $I C E R$ incremental cost-effectiveness ratio, $Q A L Y$ qualityadjusted life-year

principles stated in the Declaration of Helsinki (amended in 2008 at Seoul). The study protocol was approved by the ethics committee of Kumamoto University (approval number 1580).

\section{RESULTS}

\section{Base Case}

Switching basal insulin to degludec was associated with a mean quality-adjusted life expectancy of 0.8386 QALYs at a mean annual cost of JPY 90,757 per patient, compared with 0.8032 QALYs at a mean annual cost of JPY 81,247 per patient continuing with the previous basal insulin. This yielded an incremental cost-effectiveness ratio (ICER) of JPY 268,811 per QALY gained with degludec versus the previous basal insulin (Table 4).

\section{Sensitivity Analyses}

Switching basal insulin to degludec remained a cost-effective intervention in all sensitivity 
Table 1 Baseline characteristics of the type 2 diabetes cohort of the KIDUNA study $(N=135)$ [27]

\begin{tabular}{lc}
\hline Characteristic & Parameter \\
\hline Age, years & $63.3(12.6)$ \\
Male, $n$ (\%) & $74(54.8)$ \\
Body mass index, $\mathrm{kg} / \mathrm{m}^{2}$ & $25.0(4.0)$ \\
eGFR, $\mathrm{mL} / \mathrm{min}$ per $1.73 \mathrm{~m}^{2}$ & $66.3(22.1)$ \\
$\mathrm{HbA}_{1 \mathrm{c}}, \%(\mathrm{mmol} / \mathrm{mol})$ & $8.1(1.4)[65(15)]$ \\
Duration of diabetes, years & $15.0(8.1)$ \\
Basal insulin, $n$ (\%) & \\
Glargine U100 once-daily & $57(42.2)$ \\
Glargine U100 twice-daily & $2(1.5)$ \\
IDet once-daily & $71(52.6)$ \\
IDet twice-daily & $5(3.7)$ \\
Oral antidiabetic agents, $n(\%)$ & \\
$\alpha$-Glucosidase inhibitor & $20(14.8)$ \\
Biguanide & $27(20.0)$ \\
Thiazolidinedione & $7(5.2)$ \\
DPP-4 inhibitor & $47(34.8)$ \\
\hline
\end{tabular}

DPP-4 Dipeptidyl peptidase-4, $e G F R$ estimated glomerular filtration rate, glargine $U 100$ insulin glargine $100 \mathrm{U} / \mathrm{mL}$, $H b A_{1 c}$ glycated hemoglobin, IDet insulin detemir, KIDUNA Kumamoto Insulin Degludec Observational study

Data are presented as the mean with the standard deviation in parenthesis, unless stated otherwise

analyses, which yielded ICERs well below the willingness-to-pay threshold of JPY 5 million per QALY used in the Japanese HTA framework (Table 4). While conclusions on overall cost-effectiveness were insensitive to variations in model assumptions, individual variations in model assumptions did exert a moderate influence on the resulting ICER. The ICER was most sensitive to exclusion of the daytime hypoglycemia benefit with degludec, indicating that this was a key driver of outcomes in the base case. However, assuming the cost of biosimilar glargine in the previous basal insulin simulation arm (keeping efficacy unchanged) did not have a large impact on the resulting ICER. Combined
Table 2 Input parameters: clinical data

\begin{tabular}{llll}
\hline Parameter & $\begin{array}{l}\text { Previous } \\
\text { basal } \\
\text { insulin }\end{array}$ & Degludec & $\begin{array}{l}\text { Effect of } \\
\text { treatment } \\
\text { switch (to } \\
\text { degludec from } \\
\text { previous basal } \\
\text { insulin) }\end{array}$ \\
\hline $\begin{array}{l}\text { Insulin dose } \\
\text { units }\end{array}$ & & & Dose ratio \\
$\begin{array}{l}\text { Basal } \\
\text { Bolus }\end{array}$ & 13.8 & 13.8 & 1 \\
$\begin{array}{l}\text { Hypoglycemia } \\
\text { rate, } \\
\text { episodes per } \\
\text { PYE }\end{array}$ & 20.5 & 20.5 & 1 \\
$\begin{array}{c}\text { Daytime } \\
\text { non-severe }\end{array}$ & 10.40 & 5.36 & 0.52 \\
$\begin{array}{l}\text { Nocturnal } \\
\text { non-severe }\end{array}$ & 1.51 & 0.18 & 0.12 \\
\hline
\end{tabular}

PYE Patient-year of exposure

Non-severe hypoglycemia was defined as self-reported symptoms of hypoglycemia and/or blood glucose level of $<70 \mathrm{mg} / \mathrm{dL}(3.9 \mathrm{mmol} / \mathrm{L})$ and defined as nocturnal if occurring between 0001 and 0559 hours (both inclusive)

${ }^{a}$ Assumes mean body weight of $65 \mathrm{~kg}$

b Calculated by subtracting the number of nocturnal nonsevere episodes from the number of overall non-severe episodes, both reported by the KIDUNA study [27]

variations in model assumptions exerted a moderate influence on the resulting ICER, most notably exclusion of the daytime hypoglycemia benefit with degludec in conjunction with the cost of biosimilar glargine in the previous basal insulin simulation arm. However, conclusions on overall cost-effectiveness remained unchanged.

\section{DISCUSSION}

Our short-term modeling analysis suggests that, from a Japanese public healthcare payer perspective, switching from patients' previous basal insulin to degludec would be a cost- 
Table 3 Input parameters: costs and utilities

\begin{tabular}{lrcc}
\hline Parameter & Value & Unit & \multicolumn{1}{l}{ Source } \\
\hline Treatment costs (unit price) & & \\
Degludec $^{\mathrm{a}}$ & 8.34 & $\mathrm{JPY}$ & $\begin{array}{c}\text { NHI price } \\
\text { list }\end{array}$ \\
Glargine U100 $^{\mathrm{b}}$ & 6.45 & $\mathrm{JPY}$ & $\mathrm{NHI}$ price \\
& & & list \\
IAsp $^{\mathrm{c}}$ & 6.51 & $\mathrm{JPY}$ & NHI price \\
& & & list
\end{tabular}

Utilities

Baseline

0.8620 Utility

Sakamaki et al.

Daytime non-severe -0.0041 Disutility Evans et al. hypoglycemia

Nocturnal non- 0.0067 Disutility Evans et al. severe

hypoglycemia

Flexible dosing $\quad 0.0060$ Utility Boye et al. [39]

IAsp Insulin aspart, JPY Japanese Yen, NHI National Health Insurance

Treatment costs are reported as 2018 list prices based on the NHI drug price list

${ }^{a}$ Tresiba ${ }^{\circledR}$ (in FlexTouch ${ }^{\circledR}$ pen) (both Novo Nordisk A/S, Bagsværd, Denmark) JPY 2502 for $300 \mathrm{U}$

b Lantus ${ }^{\circledR}$ (in Solostar ${ }^{\circledR}$ pen) (both Sanofi S.A., Paris, France) JPY 1936 for 300 U

${ }^{c}$ NovoRapid $\AA$ (in FlexTouch ${ }^{\circledR}$ pen) (both Novo Nordisk A/S) JPY 1952 for $300 \mathrm{U}$

effective intervention, with an ICER substantially below the willingness-to-pay threshold of JPY 5 million per QALY used in the Japanese HTA framework [28]. Sensitivity analyses confirmed the robustness of this finding and also indicated that the daytime non-severe hypoglycemia benefit with degludec was a key driver of outcomes in the base case.

In clinical practice, patients may have the basal insulin component of their diabetes treatment regimen switched for various reasons, including lack of efficacy, unacceptable hypoglycemia rates
Table 4 Results of the base case and sensitivity analyses

\begin{tabular}{|c|c|c|c|}
\hline $\begin{array}{l}\text { Base case and } \\
\text { sensitivity analyses }\end{array}$ & $\begin{array}{l}\Delta \\
\text { Annual } \\
\text { costs } \\
(\text { JPY) }\end{array}$ & $\begin{array}{l}\Delta \\
\text { QALYs }^{\mathrm{a}}\end{array}$ & $\begin{array}{l}\text { ICER } \\
\text { (JPY per } \\
\text { QALY) }^{a}\end{array}$ \\
\hline Base case & 9510 & 0.0354 & 268,811 \\
\hline $\begin{array}{l}\text { Cost of biosimilar } \\
\text { glargine }^{\mathrm{b}} \text { in previous } \\
\text { basal insulin arm }\end{array}$ & 17,154 & 0.0354 & 484,906 \\
\hline $\begin{array}{l}\text { Excluding flexible } \\
\text { dosing utility } \\
\text { benefit }^{c}\end{array}$ & 9510 & 0.0294 & 323,715 \\
\hline $\begin{array}{l}\text { Excluding daytime } \\
\text { hypoglycemia } \\
\text { benefit }^{c}\end{array}$ & 9510 & 0.0149 & 637,827 \\
\hline $\begin{array}{l}\text { Excluding nocturnal } \\
\text { hypoglycemia } \\
\text { benefit }^{c}\end{array}$ & 9510 & 0.0265 & 359,299 \\
\hline $\begin{array}{l}\text { Cost of biosimilar } \\
\text { glargine } \mathrm{e}^{\mathrm{b}} \text { in previous } \\
\text { basal insulin arm and } \\
\text { excluding flexible } \\
\text { dosing utility benefit }\end{array}$ & 17,154 & 0.0294 & 583,945 \\
\hline $\begin{array}{l}\text { Cost of biosimilar } \\
\text { glargine }{ }^{\mathrm{b}} \text { in previous } \\
\text { basal insulin arm and } \\
\text { excluding daytime } \\
\text { hypoglycemia benefit }\end{array}$ & 17,154 & 0.0149 & 1150,568 \\
\hline $\begin{array}{l}\text { Cost of biosimilar } \\
\text { glargine } \text { in }^{\text {in previous }} \\
\text { basal insulin arm and } \\
\text { excluding nocturnal } \\
\text { hypoglycemia benefit }\end{array}$ & 17,154 & 0.0265 & 648,135 \\
\hline
\end{tabular}

ICER incremental cost-effectiveness ratio, $\Delta$ difference, QALYs quality-adjusted life-years

${ }^{a} \triangle$ Annual costs, $\triangle$ QALYs and ICERs are reported for degludec minus previous basal insulin

${ }^{b}$ Unit price of JPY 4.91 (biosimilar insulin glargine in MirioPen ${ }^{\circledR}$ [Eli Lilly and Company, Indianapolis, IN, USA] JPY 1481 for $300 \mathrm{U}$ )

${ }^{c}$ Benefit refers to difference between arms in favor of degludec versus previous basal insulin 
(which may contribute to patients not achieving glycemic targets), availability, cost and public reimbursement coverage [29]. Our study adds to a growing body of evidence that degludec is a costeffective treatment option in various patient populations with diabetes, in this case in patients with T2D receiving basal-bolus insulin therapy who have the basal insulin component of their regimen switched to degludec, from a Japanese public healthcare payer perspective.

This analysis represents the first published CEA of degludec from a Japanese public healthcare payer perspective. Our findings share similarities with the results of several global short-term CEAs of degludec versus glargine U100 from public healthcare payer perspectives, which have also reported that degludec is a costeffective treatment alternative in patients with T2D receiving basal-bolus therapy, in their respective settings [19-22, 24, 25]. Healthcare in Europe is provided through a wide range of different systems run at individual national levels. The UK has a tax-based healthcare system, whereas healthcare in Japan is provided through a multi-payer social insurance-based system. In Japan, public reimbursement prices for drugs are set as an official price applicable to all healthcare providers and are regularly revised [30]. In contrast, in the UK, drug list prices often do not reflect the actual cost paid because discounts may be negotiated, for instance through patient access schemes and, consequently, treatment costs may be overestimated if based on list prices.

Most analyses, including the present study, have focused on the short-term effects of insulin dosing and hypoglycemia rates over a 1-year time horizon, and identified hypoglycemia benefits as a large driver of QALY gains with degludec. Pollock et al. reported that severe hypoglycemia was a key driver of QALY gains in their short-term analysis, which also captured cardiovascular outcomes and mortality, in addition to severe hypoglycemia rates and insulin dosing, over a 2-year time horizon [19]. There are limited data available on the longterm cost effectiveness of degludec versus glargine U100. Most CEAs of insulins are informed by clinical trial data, and the treat-to-target design of clinical trials often results in non- inferior or non-significant differences in glycemic control between treatment arms and, thus, renders long-term modeling based on $\mathrm{HbA}_{1 \mathrm{c}}$ differences non-informative. In their analysis, Pollock et al. performed a sensitivity analysis including additional long-term costs and effects over patient lifetimes that demonstrated similar findings to the main analysisthat, as part of a basal-bolus insulin regimen, degludec was highly cost-effective versus glargine U100 in patients with T2D at high risk of cardiovascular events [19].

Our analysis has provided a conservative estimate of the cost-effectiveness of switching from basal insulin to degludec, as there were no costs associated with non-severe hypoglycemic events due to the lack of Japanese-specific data available in the literature. Although severe hypoglycemic events requiring hospitalization can pose a significant financial burden on healthcare systems [31], there are also moderate costs associated with non-severe events relating to an elevated use of consumables, such as selfmeasured blood glucose tests or additional visits to healthcare professionals, that need to be considered [32]. Hypoglycemia exerts significant societal costs through lost productivity related to absences from work that were not reflected by our CEA from a public healthcare payer perspective [33]. Furthermore, fear of hypoglycemia may promote compensatory behaviors in order to avoid future events, such as non-adherence to therapy or decreasing the insulin dose, which can result in poor glycemic control and an increased risk of diabetes-related complications [9, 34, 35].

To date, most global short-term CEAs of degludec versus glargine U100 have been informed by data from treat-to-target RCTs. The present analysis was based on Japanese realworld evidence (RWE) from the KIDUNA study, in which patients switched basal insulin from either glargine U100 or IDet (assuming the basal insulin cost of glargine U100) to degludec, under conditions of routine clinical practice. RWE can provide insights beyond those addressed by RCTs and are often the sole source of evidence concerning the effects of a medical intervention in community practice, with applications for healthcare decision-making [36]. 
This analysis was subject to limitations, including the observational design of the KIDUNA study and the lack of an active comparator arm, both of which present the possibility of confounding. Other limitations to the KIDUNA study include the small study size and self-reporting of hypoglycemia. A general limitation when conducting CEAs of diabetes treatments in Japanese settings is the current paucity of disutility estimates associated with hypoglycemic events for Japanese patients in the literature, which necessitated the application of disutilites reported by comprehensive overseas studies in our analysis. While microvascular and macrovascular complications can have sizeable effects on diabetes-related treatment costs and patient quality-of-life, they were not included in the present analysis. Data on these events were not collected in the KIDUNA study, while the costs and effects associated with these complications may accrue over long timeframes that are outside of the scope of the present short-term modeling analysis.

Key strengths of the present analysis are its simplicity, transparency and homogeneity of model inputs from Japanese sources, which included sourcing clinical outcomes and baseline characteristics to inform the model from the T2D cohort of the KIDUNA study. The base case was highly conservative, only using endpoints from the KIDUNA study with significant differences between treatment arms and assuming no costs associated with non-severe hypoglycemia.

\section{CONCLUSION}

Based on Japanese RWE, our short-term modeling analysis suggests that switching Japanese patients with T2D receiving a basal-bolus regimen from their previous basal insulin to degludec would be highly cost-effective. These data may help decision-makers in Japan to allocate healthcare resources efficiently.

\section{ACKNOWLEDGEMENTS}

The authors thank the staff and patients for their participation in the KIDUNA study.
Funding. Sponsorship for this study and article processing charges were funded by Novo Nordisk Pharma Ltd. Japan. All authors had full access to all of the data in this study and take complete responsibility for the integrity of the data and accuracy of the data analysis.

Medical Writing and Editorial Assistance. Medical writing and editorial support were provided by Anna Campbell, PhD, and Richard McDonald, of Watermeadow Medical, an Ashfield company, part of UDG Healthcare plc and funded by Novo Nordisk.

Authorship. All named authors meet the International Committee of Medical Journal Editors (ICMJE) criteria for authorship for this manuscript, take responsibility for the integrity of the work as a whole, and have given final approval to the version to be published.

Prior Presentation. Parts of this analysis were presented as a poster presentation at the International Society for Pharmacoeconomics and Outcomes Research, 21st Annual European Congress, 10-14 November 2018, Barcelona, Spain.

Disclosures. Jakob Langer is an employee of Novo Nordisk Pharma Ltd. Michael L Wolden is an employee of Novo Nordisk A/S. Seiya Shimoda has received lecture fees from Daiichi Sankyo Inc., MSD K.K. and Novo Nordisk Pharma. Eiichi Araki has participated on advisory panels for Alcon, Astellas Pharma, Astra Zeneca, Eli Lilly, Kowa Pharmaceutical, Nippon Boehringer Ingelheim, Novo Nordisk Pharma, Sanofi and Terumo Corporation, has received honoraria for lectures from Astellas Pharma, MSD, Ono Pharmaceutical, Novo Nordisk Pharma and Sanofi, and scholarship grants from Astellas Pharma, Daiichi Sankyo, Mitsubishi Tanabe Pharma, Nippon Boehringer Ingelheim, Novo Nordisk Pharma, Ono Pharmaceutical, Sanofi, Shionogi, Sumitomo Dainippon Pharma and Takeda Pharmaceutical. Miki Sato has nothing to disclose.

Compliance with Ethics Guidelines. All participants provided written, informed 
consent to participate in the KIDUNA study, which was carried out in accordance with the principles stated in the Declaration of Helsinki (amended in 2008 at Seoul). The study protocol was approved by the ethics committee of Kumamoto University (approval number $1,580)$.

Data Availability. The datasets generated during and/or analyzed during the current study are available from the corresponding author on reasonable request.

Open Access. This article is distributed under the terms of the Creative Commons Attribution-NonCommercial 4.0 International License (http://creativecommons.org/licenses/ by-nc/4.0/), which permits any noncommercial use, distribution, and reproduction in any medium, provided you give appropriate credit to the original author(s) and the source, provide a link to the Creative Commons license, and indicate if changes were made.

\section{REFERENCES}

1. Organization for Economic Co-operation and Development (OECD). How does Japan compare. 2017. https://www.oecd.org/japan/Health-at-a-Glance2017-Key-Findings-JAPAN-in-English.pdf. Accessed Sept 2018.

2. Sakamoto H, Rahman M, Nomura S, et al. Japan health system review. World Health Organization. Regional Office for South-East Asia, 2018. p. 16-63.

3. Shiroiwa T, Fukuda T, Ikeda S, Takura T, Moriwaki K. Development of an official guideline for the economic evaluation of drugs/medical devices in Japan. Value Health. 2017;20:372-8.

4. Turner S, Chase DL, Milne R, et al. The health technology assessment adaptation toolkit: description and use. Int J Technol Assess Health Care. 2009;25[Suppl 2]:37-41.

5. Weinstein MC, O'Brien B, Hornberger J, et al. Principles of good practice for decision analytic modeling in health-care evaluation: report of the ISPOR Task Force on Good Research PracticesModeling Studies. Value Health. 2003;6:9-17.
6. International Diabetes Federation. IDF diabetes atlas. 8th ed. Brussels: International Diabetes Federation; 2017.

7. Charvat H, Goto A, Goto M, et al. Impact of population aging on trends in diabetes prevalence: a meta-regression analysis of 160,000 Japanese adults. J Diabetes Investig. 2015;6:533-42.

8. Cryer PE. The barrier of hypoglycemia in diabetes. Diabetes. 2008;57:3169-76.

9. Frier BM, Jensen MM, Chubb BD. Hypoglycaemia in adults with insulin-treated diabetes in the UK: selfreported frequency and effects. Diabet Med. 2016;33:1125-32.

10. Harris S, Mamdani M, Galbo-Jorgensen CB, Bogelund M, Gundgaard J, Groleau D. The effect of hypoglycemia on health-related quality of life: Canadian results from a multinational time tradeoff survey. Can J Diabetes. 2014;38:45-52.

11. Whitmer RA, Karter AJ, Yaffe K, Quesenberry CP Jr, Selby JV. Hypoglycemic episodes and risk of dementia in older patients with type 2 diabetes mellitus. JAMA. 2009;301:1565-72.

12. Zoungas S, Patel A, Chalmers J, et al. Severe hypoglycemia and risks of vascular events and death. N Engl J Med. 2010;363:1410-8.

13. Zinman B, Marso SP, Christiansen E, Calanna S, Rasmussen S, Buse JB. Hypoglycemia, cardiovascular outcomes, and death: the LEADER experience. Diabetes Care. 2018;41:1783-91.

14. Heise T, Nosek L, Bottcher SG, Hastrup H, Haahr H. Ultra-long-acting insulin degludec has a flat and stable glucose-lowering effect in type 2 diabetes. Diabetes Obes Metab. 2012;14:944-50.

15. Ratner RE, Gough SC, Mathieu C, et al. Hypoglycaemia risk with insulin degludec compared with insulin glargine in type 2 and type 1 diabetes: a preplanned meta-analysis of phase 3 trials. Diabetes Obes Metab. 2013;15:175-84.

16. Marso SP, McGuire DK, Zinman B, et al. Efficacy and safety of degludec versus glargine in type 2 diabetes. N Engl J Med. 2017;377:723-32.

17. Wysham C, Bhargava A, Chaykin L, et al. Effect of insulin degludec vs insulin glargine U100 on hypoglycemia in patients with type 2 diabetes: the SWITCH 2 randomized clinical trial. JAMA. 2017;318:45-56.

18. Lane W, Bailey TS, Gerety G, et al. Effect of insulin degludec vs insulin glargine u100 on hypoglycemia in patients with type 1 diabetes: the SWITCH 1 randomized clinical trial. JAMA. 2017;318:33-44. 
19. Pollock RF, Valentine WJ, Marso SP, et al. DEVOTE 5: evaluating the short-term cost-utility of insulin degludec versus insulin glargine U100 in basal-bolus regimens for type 2 diabetes in the UK. Diabetes Ther. 2018;9:1217-32.

20. Pollock RF, Tikkanen CK. A short-term cost-utility analysis of insulin degludec versus insulin glargine U100 in patients with type 1 or type 2 diabetes in Denmark. J Med Econ. 2017;20:213-20.

21. Evans M, Chubb B, Gundgaard J. Cost-effectiveness of insulin degludec versus insulin glargine in adults with type 1 and type 2 diabetes mellitus. Diabetes Ther. 2017;8:275-91.

22. Mezquita-Raya P, Darba J, Ascanio M, Ramirez de Arellano A. Cost-effectiveness analysis of insulin degludec compared with insulin glargine U100 for the management of type 1 and type 2 diabetes mellitus-from the Spanish National Health System perspective. Expert Rev Pharmacoecon Outcomes Res. 2017;17:587-95.

23. Woo V, Zinman B, Pieber TR, et al. Short-term costeffectiveness of insulin degludec vs. insulin glargine 100 units/mL for patients with type 2 diabetes at high risk of hypoglycemia in DEVOTE. Can J Diabetes. 2018;42[Suppl]:S60.

24. Evans M, Wolden M, Gundgaard J, Chubb B, Christensen T. Cost-effectiveness of insulin degludec compared with insulin glargine in a basal-bolus regimen in patients with type 1 diabetes mellitus in the UK. J Med Econ. 2015;18:56-68.

25. Lalić N, Russel-Szymczyk M, Culic M, Tikkanen CK, Chubb B. Cost-effectiveness of insulin degludec versus insulin glargine U100 in patients with type 1 and type 2 diabetes mellitus in Serbia. Diabetes Ther. 2018; 9(3):1201-16.

26. Evans M, Wolden M, Gundgaard J, Chubb B, Christensen T. Cost-effectiveness of insulin degludec compared with insulin glargine for patients with type 2 diabetes treated with basal insulinfrom the UK health care cost perspective. Diabetes Obes Metab. 2014;16:366-75.

27. Shimoda S, Sato M, Sekigami T, et al. A 1-year, prospective, observational study of Japanese outpatients with type 1 and type 2 diabetes switching from insulin glargine or detemir to insulin degludec in basal-bolus insulin therapy (Kumamoto Insulin Degludec Observational study). J Diabetes Investig. 2016;7:703-10.

28. Kristensen F, Igarashi A, Neumann PJ, Goldman DP. Challenges and best practices for the Japan Health Technology Assessment pilot program. Value Outcomes Spotlight. 2018;4:40-1.
29. Anderson SL, Trujillo JM, Anderson JE, Tanenberg RJ. Switching basal insulins in type 2 diabetes: practical recommendations for health care providers. Postgrad Med. 2018;130:229-38.

30. Takayama A, Narukawa M. Pharmaceutical pricing and reimbursement in Japan: for faster, more complete access to new drugs. Ther Innov Regul Sci. 2016;50:361-7.

31. Holbrook T, Tang Y, Das R, et al. Direct medical costs of severe hypoglycaemic events in patients with type 2 diabetes in England: a retrospective database study. Int J Clin Pract. 2017;71:e12958.

32. Foos V, Varol N, Curtis BH, et al. Economic impact of severe and non-severe hypoglycemia in patients with Type 1 and Type 2 diabetes in the United States. J Med Econ. 2015;18:420-32.

33. Geelhoed-Duijvestijn PH, Pedersen-Bjergaard U, Weitgasser R, Lahtela J, Jensen MM, Ostenson CG. Effects of patient-reported non-severe hypoglycemia on healthcare resource use, work-time loss, and wellbeing in insulin-treated patients with diabetes in seven European countries. J Med Econ. 2013;16:1453-61.

34. Fidler C, Elmelund CT, Gillard S. Hypoglycemia: an overview of fear of hypoglycemia, quality-of-life, and impact on costs. J Med Econ. 2011;14:646-55.

35. Ohashi Y, Wolden ML, Hyllested-Winge J, Brod M. Diabetes management and daily functioning burden of non-severe hypoglycemia in Japanese people treated with insulin. J Diabetes Investig. 2017;8:776-82.

36. Berger ML, Sox H, Willke RJ, et al. Good practices for real-world data studies of treatment and/or comparative effectiveness: recommendations from the joint ISPOR-ISPE special task force on real-world evidence in health care decision making. Value Health. 2017;20:1003-8.

37. Sakamaki H, Ikeda S, Ikegami N, et al. Measurement of HRQL using EQ-5D in patients with type 2 diabetes mellitus in Japan. Value Health. 2006;9:47-53.

38. Evans M, Khunti K, Mamdani M, et al. Health-related quality of life associated with daytime and nocturnal hypoglycaemic events: a time trade-off survey in five countries. Health Qual Life Outcomes. 2013;11:90.

39. Boye KS, Matza LS, Walter KN, Van BK, Palsgrove AC, Tynan A. Utilities and disutilities for attributes of injectable treatments for type 2 diabetes. Eur J Health Econ. 2011;12:219-30. 